\title{
The effects of conflict role and intensity on preschoolers' expectations about peer conflict
}

\author{
Kevin M. David, Bridget C. Murphy, Janett M. Naylor, \\ and Kim M. Stonecipher \\ University of Oklahoma, Norman, OK, USA
}

\begin{abstract}
Using a puppet procedure depicting hypothetical conflict involving the participant and a peer, 96 preschoolers' ( 48 boys and 48 girls; $M=5.14$ years, $S D=0.78$ years) expectations about peer conflict were assessed as a function of their role in the conflict (i.e., initiator of or responder to initial provocation) and the intensity level of the conflict. Initiators of conflict expected less conflict escalation and subsequent problems with the same peer from the conflict than did responders, particularly following low-intensity conflict. Findings also indicated that, for low-intensity but not high-intensity conflict, girls expected the same peer to provoke them during a subsequent interaction more often than did boys. Results provide further support for assessing preschoolers' understanding of conflict and are consistent with previous work demonstrating a self-serving bias in young children's perceptions and reports of their conflicts with other children. Moreover, findings are discussed in terms of their implications for the development of peer relations.
\end{abstract}

Researchers have long theorised about the developmental significance of interpersonal conflict with peers (e.g., Piaget, 1932; Shantz \& Hobart, 1989), and a large body of research exists regarding children's behavioural, emotional, and socialcognitive reactions to peer conflict (e.g., Eisenberg \& Garvey, 1981; Laursen \& Hartup, 1989; Murphy \& Eisenberg, 2002; Shantz, 1987, 1993). Conflict has been defined as mutual opposition between children such that child A does or says something that child B disputes, and then child A responds to child B with counteropposition (Shantz, 1987). Thus, there is an initiator of initial opposition (A) and a responder to the initial opposition (B). When asked who initiated particular conflicts, children typically blame the other child (McGuire, Manke, Eftekhari, \& Dunn, 2000; Shantz, 1993). Although children's view of who started the conflict is important for guiding their reactions, children's actual role in the conflict (i.e., initiator of or responder to initial opposition) is also believed to play a key role in determining their reactions during conflict as well as subsequent interactions with the same peer (e.g., Arsenio \& Killen, 1996). Nonetheless, Murphy and Eisenberg (1997) noted that researchers primarily have focused on the recipients of provocation such that further work is needed to understand the different experiences of initiators and responders during conflict. Moreover, although the effects of conflict role may vary as a function of other aspects of the situation such as the intensity of the conflict, little attention has been given to how these contextual variables might interact to contribute to young children's expectations about conflict. Thus, the present study was designed to extend previous work by examining the effects of conflict role and intensity on preschoolers' expectations about conflict using hypothetical puppet vignettes depicting peer conflict.
Conflict role is expected to influence children's expectations about conflict, in part, because children are likely to view conflicts they initiate in a more positive manner than those in which they are initially provoked and respond with subsequent opposition. Preschoolers in general tend to possess unrealistically positive self-concepts and self-evaluations (see Harter, 1998). These positive self-views may well be manifested in specific contexts, such as interpersonal conflict. Indeed, Arsenio and Lover (1995) hypothesised that young children's immature cognitive abilities are likely to lead them to focus on material gains and positive outcomes for themselves rather than on the other child's loss or negative affect when they victimise a peer or initiate a conflict. In contrast, young children are likely to focus on their material loss and negative emotion when they are the victim of a peer's transgression or are the recipient of a peer's opposition, resulting in more negative appraisals of the situation.

Young children's reports of actual conflicts, as well as their emotional expressions and behaviours during naturally-occurring peer conflict, indicate that they do not view conflicts that they initiate as particularly oppositional or negative. Specifically, Ross and colleagues found that when reporting on a recent conflict with a sibling, preschoolers and school-aged children demonstrated a self-serving bias by citing more transgressions for the other child than for themselves (Ross, Ross, Wilson, \& Smith, 1999; Ross, Smith, Spielmacher, \& Recchia, 2004; Wilson, Smith, Ross, \& Ross, 2004). Children also tended to justify their own transgressions by minimising the damage they inflicted on other children, whereas their descriptions maximised the harm done by the other children and emphasised others' malicious intentions. Moreover, preschoolers who initiate opposition and aggression toward
Correspondence should be sent to Kevin M. David, Department of Psychology, University of Puget Sound, 1500 N. Warner, Tacoma, WA 98416, USA; e-mail: kdavid@ups.edu.
The authors thank the parents, teachers, administrators, and children at KinderCare and Children's World as well as Taniesha Woods, Melissa Findley, and Allison Doonkeen, who assisted with this study. Kevin M. David is now at the University of Puget Sound. 
peers express more positive emotion (i.e., joy/happiness) and less negative emotion (i.e., a composite score of anger and sadness, Arsenio, Cooperman, \& Lover, 2000; and of anger, sadness, fear, and surprise, Arsenio \& Killen, 1996) than recipients during and immediately following opposition. Preschoolers also expect victims of psychological harm to be angrier than the victimisers in hypothetical moral transgressions among peers (Smetana, Daddis, Toth, Cicchetti, Bruce, \& Kane, 1999). Further, preschoolers perceive unprovoked transgressions to be more serious and punishable than transgressions that are provoked by another child's actions (Smetana et al., 1999; Smetana, Campione-Barr, \& Yell, 2003) and they tend to condone aggression in defence of one's possessions (Hay, Zahn-Waxler, Cummings, \& Iannotti, 1992), suggesting that they believe retribution in response to provocation is somewhat morally justified (Astor, 1994). Thus, when preschoolers respond to initial provocation by a peer they are likely to report more negative expectations regarding the conflict (i.e., expectations of conflict escalation and mad reactions) than when they initiate conflict.

In addition to the effects of conflict role on young children's expectations about conflict, children's role may affect their expectations of future interactions with the peer with whom they were in conflict. Indeed, preschoolers use their knowledge of how a hypothetical peer behaved previously to inform their predictions about how that peer will act in the future, such that their predictions are consistent with previously provided information regarding a target peer (Berndt \& Heller, 1985; Dozier, 1991; Yuill \& Pearson, 1998). Therefore, when young children are responders to initial opposition during conflict they are likely to expect the same peer to provoke them again during subsequent interactions. Moreover, young children understand that their own behaviours and internal states are typical, frequent, and stable (Eder, 1989), suggesting that when children initiate conflict they are likely to expect themselves to continue to be negative towards the same peer during subsequent interactions. However, initiators may expect subsequent interactions with the same peer to be relatively constructive because they view themselves positively in the context of conflict (Ross et al., 1999, 2004; Wilson et al., 2004). Consequently, it is unclear whether initiators of a given conflict will expect subsequent problems with the same peer.

Although children's conflict role seems to influence their expectations about conflict and about subsequent interactions with the same peer, the effects of conflict role may vary as a function of the intensity of the conflict. The overall intensity of a conflict reflects emotional as well as behavioural intensity and refers to the level of negativity, threat, and destructiveness in the children's expressed opposition (e.g., tone, words, actions, emotional expressions). Preschoolers' conflicts that are high in affective intensity are longer in duration, involve more aggression, and more often result in discontinued peer interaction or subsequent conflictual exchanges than lowintensity conflicts (Laursen \& Hartup, 1989; O’Brien, Roy, Jacobs, Macaluso, \& Peyton, 1999). Further, in response to hypothetical situations, young children perceive hitting in response to being teased as more serious and deserving of punishment than teasing in response to being teased (Smetana et al., 2003), demonstrating that children view oppositions high in behavioural intensity as being particularly negative. Thus, preschoolers are likely to report more negative expectations regarding conflict (i.e., expectations of conflict escalation, mad reactions, and subsequent problems) following highintensity than following low-intensity conflict.

Moreover, the effects of conflict role may vary across intensity levels. Although the interaction between conflict role and affective intensity was not specifically tested, O'Brien et al. (1999) found that for initiators but not for recipients of initial provocation, conflicts followed by subsequent conflicts were more intense than conflicts followed by unoccupied activity (e.g., watching the other child but not interacting). Given the nature of high-intensity conflicts, children are likely to be particularly focused on negative aspects of the interaction and form negative perceptions of the dispute. In addition, intense negative emotion (O'Brien et al., 1999) and nonconstructive behaviour (Eisenberg \& Garvey, 1981) by one child tends to be followed by further negativity from the other child throughout conflict. Therefore, who started the dispute may not be as influential in high-intensity conflicts as in low-intensity conflicts. In contrast, during low-intensity conflicts that involve moderately expressed opposition, conflict role may have a significant impact because young children may perceive such interactions as oppositional only when a peer provokes them. Thus, the effects of conflict role on children's expectations about conflict and subsequent interactions may not be as strong for high-intensity conflicts as for low-intensity conflicts.

To examine children's expectations about conflict and subsequent interactions following peer conflict in the present study, preschoolers used puppets to enact their responses in four hypothetical conflicts that were either initiated by them or by the peer. Vignettes depicted high-intensity conflict or lowintensity conflict. High-intensity conflicts included negative verbal expression, a harsh tone, and threatening dialogue, whereas low-intensity conflicts were relatively mild and lacked negative verbal expression, harshness, and threatening discourse. Following the scripted part of each conflict vignette, children were asked to finish the story (i.e., expectation of conflict escalation) and to report how mad they would be during the conflict. After responding to each conflict vignette, children participated in a "later that day" vignette depicting a subsequent interaction with the same peer from the conflict and they were asked about what would happen during the interaction. The use of hypothetical vignettes allowed for the control and manipulation of the children's conflict roles as well as the intensity levels of the conflict and ensured that the mutual opposition component of conflict (Shantz, 1987) occurred during each interaction.

Based on previous research (e.g., Arsenio \& Killen, 1996; Laursen \& Hartup, 1989; Smetana et al., 1999), conflict responders were expected to report more negative expectations about the conflict (i.e., expectations of conflict escalation and mad reactions) and more expectations of subsequent problems than were conflict initiators, and it was predicted that highintensity conflict would elicit more negative expectations than low-intensity conflict. Yet, it also was expected that children would report relatively negative expectations following highintensity conflict, regardless of their conflict role, but that responders would report more negative expectations than would initiators following low-intensity conflict. Finally, gender also was considered, as girls' greater concern with affiliation and maintaining interpersonal harmony (see Ruble \& Martin, 1998) may lead them to be particularly sensitive to events that disrupt relationships and to the oppositional nature of peer conflict. Indeed, adolescent girls expect peer conflict to have more negative implications for their relationships (e.g., 
conflict will make the relationship worse) than do boys (Laursen, 1993). However, girls' responses to conflict are generally prosocial, constructive, and relatively unlikely to have a negative impact on peer relations (Hay et al., 1992; P.M. Miller, Danaher, \& Forbes, 1986; Murphy \& Eisenberg, 2002; Rose \& Asher, 1999). Given that girls' conflict reactions reduce the likelihood of negative consequences yet they tend to expect negative outcomes, it was unclear whether the effects of conflict role and intensity would differ for boys and girls and so no specific predictions were made regarding gender. In sum, the present study extends prior work by examining whether children's actual role in conflict influences their expectations of peer conflict and their expectations for interactions following conflict. Furthermore, this study is one of the first examinations of the interactive effects of conflict role and intensity on children's responses to conflict.

\section{Method}

\section{Participants}

To recruit participants for this study, the authors spoke with parents at two local day-care facilities as they picked up their children. Parents of approximately $90 \%$ of the children provided permission for their children's participation. Specifically, 96 children ( 48 boys and 48 girls; $M$ age $=5.14$ years, $S D=0.78$ years, range $=4.00-6.92$ years $)$ participated. Children were predominately Caucasian (81\%), whereas the remaining children were Asian (4\%), African-American (4\%), Native-American (4\%), Hispanic (1\%), and other or mixed $(6 \%)$. The majority of the children lived in two-parent households with no stepparents $(69 \%)$ and the remaining children lived in single-parent households (23\%), two-parent households with a stepparent (5\%), and extended family households $(3 \%)$. The mean income of the children's households was $\$ 68,472(S D=\$ 49,204)$ and mean education levels were 15.7 years $(S D=2.10)$ for mothers and 15.5 years $(S D=$ 3.10) for fathers.

\section{Procedure}

Children were taken individually to a separate room in the daycare centre to participate in the puppet procedure with the experimenter. The puppet procedure/interview was audiotaped and lasted approximately 20 minutes. After each vignette, children received one sticker such that they received a total of four stickers.

\section{Conflict vignettes}

Children participated in a series of hypothetical conflict vignettes involving two puppets, one of which represented the participant and the other represented a peer (i.e., "another kid"). This procedure was adapted from previous research using hypothetical puppet vignettes (Eisenberg, Fabes, Minore, Mathy, Hanish, \& Brown, 1994; Mize \& Ladd, 1988; Murphy \& Eisenberg, 1997). Children participated in four conflict vignettes designed to reflect typical problematic interactions between young children and to fit with the definition of conflict as mutual opposition (Shantz, 1987). The experimenter portrayed each vignette and asked the child to finish each of the stories. Specifically, the experimenter started each vignette by telling the child, 'I'm going to start the story and you will help me finish it." The scripted part of each vignette involved one child initiating a conflict with another child, followed by an escalating response from the other child, and ending with an escalating response from the initiator; thus, each conflict remained unfinished at the end of each vignette. As is discussed shortly, participants' role in the conflict (i.e., initiator of or responder to initial provocation) was manipulated, as was the intensity level of the conflicts. To assess children's expectations about subsequent interactions with the peers in the conflicts, children participated in a brief "later that day" vignette after each conflict vignette. Specifically, the vignette occurred "later that day," referring to the day of the corresponding conflict vignette, and involved the participant playing with a similar toy that was involved in the conflict and the peer approaching the child. Children received a sticker after each "later that day" vignette to break up the procedure between vignettes and increase the likelihood that the children would treat the vignettes as separate incidents.

The four conflicts and their corresponding "later that day" vignettes were presented in random order and involved the following situations: (1) the children are playing blocks together and one child takes the other child's block and they argue about the block; the "later that day" vignette involved the "other child" approaching as the participant plays with legos; (2) the children's class gets a new rabbit and one child takes the rabbit away from the other child and they argue over the rabbit; the "later that day" vignette involved the "other child" approaching as the participant plays with a hamster; (3) the children are cleaning up some toys and one child orders the other child to pick up the toys and they argue about cleaning; the "later that day" vignette involved the "other child" approaching as the participant picks up some books; (4) the children are playing store and they argue about who should work the cash register and who should be the customer; the "later that day" vignette involved the "other child" approaching as the participant plays school. For example, the store vignette was presented as follows: "You and another kid are playing store together. You say, 'I'll do the cash register and you have to be the customer.' The other kid says, 'No. I want to do the cash register.' You say, 'You have to be the customer; I did it last time.' " The corresponding "later that day" school vignette was presented as follows: "Later that day, you are playing school and you're the teacher. The same kid you had a problem with before with the cash register comes up to you." All of the vignettes were presented in the same manner. Props (e.g., blocks, cash register) were used to increase the children's involvement in the vignettes.

Conflict role was a between-subjects variable such that approximately half of the children heard vignettes in which they initiated the conflict situation and approximately half of the children were responders to the initial provocation in the stories. In the "initiator" condition, the participant initiated a conflict in each vignette by provoking the "other child" (e.g., "You and another kid are playing store together and you say, 'you have to be the customer or I'm not playing"'), whereas the "other child" initiated the conflict in the "responder" condition (e.g., "You and another kid are playing store together and the other kid says, 'you have to be the customer or I'm not playing"'). For each condition, the child who initiated the conflict also made the final response in each scripted vignette.

Intensity was a within-subjects variable such that each child 
heard two low-intensity conflict vignettes and two highintensity vignettes. To manipulate the intensity of the conflicts, the scripted verbalisations and actions of each child in the vignette varied, as did the word emphasis and tone of the experimenter's portrayal. Specifically, in the low-intensity conflicts, the puppets' tone, words, and actions were oppositional and slightly irritated, but involved little negative emotional expression or threatening actions (e.g., "You say, 'I need another block' and take one of the other kid's blocks"). In contrast, the high-intensity conflicts were oppositional and involved a harsh tone reflecting negative emotional expression, as well as more demands and threatening behaviours than the low-intensity conflicts (e.g., "You say, 'Give me that block!' and grab a block out of the other kid's hands"). Further, the experimenters moved their puppet's head when the "other kid" was speaking in the low-intensity condition but moved the puppet's entire body forwards and backwards in the highintensity vignettes. However, the volume level of the experimenters' voice remained relatively constant across the two intensity conditions and the experimenters displayed a neutral facial expression across all conditions. To ensure that the vignettes would be portrayed as intended, experimenters underwent extensive training for several weeks prior to data collection. Specifically, experimenters were trained to maintain a constant volume level and neutral facial expression throughout the entire procedure while adjusting their tone, word emphasis, and puppet movements to correspond to the condition.

Each of the four conflict situations discussed previously had low- and high-intensity versions, each varying in whether the participant was the initiator or the responder in the conflict. Thus, there were a total of 16 different vignettes (i.e., initiator/ low-intensity, initiator/high-intensity, responder/low-intensity, responder/high-intensity) and each child heard 4 vignettes (in random order; two low- and two high-intensity) in which they were either the initiator or the responder in the conflict.

The "later that day" vignettes did not involve any manipulation. They were relatively mild and neutral (i.e., presented without any negative verbal expression or harsh tone) across all conditions. In these vignettes, the experimenter read the script while moving the "other kid" puppet closer to where the child's puppet was playing to portray that the peer was approaching the child in a neutral manner. Experimenters were trained for several weeks to present all of the "later that day" vignettes similarly.

To present the puppet vignettes, experimenters gave children a puppet to put on their hand and told the children that their puppet was going to be them in the stories. Experimenters also put a puppet on their own hand and told the children that the experimenter's puppet represented "another kid." The participants' puppet and the "other child" puppet looked similar to one another; each puppet had an orange body that resembled a shirt. In addition, the puppets' mouths were removed for all conditions so they would not convey any emotional expression. When necessary, the experimenters helped the children put their puppet on their hand and showed the children how to move the puppet. The experimenter would put his/her hand on the child's puppet and guide them in the scripted actions of the vignette so that each child performed the same acts during the vignette. For example, when the children were playing with blocks in one of the vignettes, the experimenter would help the child pick up a block by gently moving the child's puppet to show him/her how to grasp the block with the puppet. Experimenters referred to the puppets as "you" and the "other kid" throughout each vignette. As the experimenters read the vignettes, they moved the "other child" puppet to correspond with each story and helped the children move their puppet for the scripted actions in each vignette. To ensure that the children's responses were clear, experimenters repeated all of the children's responses verbatim and described in detail all of the children's actions with the puppets.

After each conflict vignette, children were asked a number of questions assessing their expectations about the conflict situation. To assess children's expectation regarding the ending of the conflict, children were asked, "What would happen next?" after the scripted part of each conflict vignette. If they did not respond, the experimenters told the children to "Show me with the puppets." Following the scripted part of the vignette, children also were asked, "Would you be mad when this happened?" If they said yes, they were asked, "How mad would you be?" and were instructed to show the experimenter how mad they would be using a scale of three faces illustrating varying degrees of anger $(3=$ really mad, $2=$ kind of mad, $1=$ a tiny bit mad, and $0=$ responded " $n o$ "). Before the children responded to this item, experimenters pointed to each face and explained what each one meant and then asked the children if they understood what the faces meant (e.g., "This face means you would be really mad"). The order of the presentation of the faces was counterbalanced across children (from "really mad" or from "a tiny bit mad"). Also, to assess children's perception of the conflict initiator, participants were asked, "Who started the problem you just had?"

Following the scripted part of each "later that day" vignette, experimenters asked the children about their expectations for subsequent interaction with the same child who was involved in the conflict. Specifically, children were asked, "What would happen next?" As with the conflict vignettes, if children did not respond, they were told to "Show me with the puppets."

\section{Data coding}

Following data collection, children's responses to the vignettes were transcribed. A trained research assistant coded the intensity of the experimenters' verbal presentation of the vignettes from the audiotape. In addition, a trained research assistant coded the participants' transcribed responses to the questions "What would happen next?" and "Who started the problem you just had?" following the conflict vignettes as well as their responses to "What would happen next?" following the "later that day" vignettes. A second independent assistant also coded approximately $25 \%$ of the experimenters' presentations of the vignettes and the children's responses to obtain reliability. Children's responses to the two low-intensity vignettes were combined, as were responses to the two highintensity vignettes, to create composite scores that were used in all subsequent analyses. Some variables (i.e., expectations of conflict escalation, mad reactions, intensity of conflict vignettes) were combined and averaged across vignettes, whereas proportion scores were created across vignettes for other variables (i.e., perceptions of conflict initiator and expectations of subsequent provocation by peer and self).

Intensity of conflict vignettes. To determine whether the lowand high-intensity conflicts verbally depicted different levels of intensity as intended, a trained research assistant not involved 
in data collection and blind to the conditions and hypotheses of the study rated the intensity of the experimenters' audiotaped presentation of the vignettes using tone of voice, word emphasis, and content. The coder used a 5-point rating scale ( 1 = mild tone and absence of negativity and intensity; $3=$ somewhat negative tone and moderately intense; $5=$ very negative tone and very intense), $r(118)=.87, p<.001$.

Expectations of conflict escalation. Children's responses to the "What would happen next?" question immediately following the conflict vignettes were coded on a 5-point scale reflecting their expectations of conflict escalation. This code reflected the extent to which the children expected the conflict to escalate or de-escalate following the scripted part of the vignette ( 1 = very likely to de-escalate and lead to positive outcome, e.g., "We would take turns playing with the bunny," "We would be nice"; 3 = somewhat likely to escalate and somewhat likely to de-escalate, e.g., "We would each play with our own toys," "We would walk away"; 5 = very likely to escalate and lead to negative outcome, e.g., "We would start fighting again," "We would yell at each other"), $r(92)=.92, p<.001$.

Perceptions of conflict initiator. Responses to "Who started the problem you just had?" were coded 0 for "other child" and 1 for "participant." Scores reflecting the proportion of times the children reported that they, rather than the peer, started the conflict were created and used in subsequent analyses.

Expectations of subsequent provocation. Children's responses to "What would happen next?" following the "later that day" vignettes were coded for whether they expected subsequent provocation to occur. The general "What would happen next?" question was used rather than a specific question (e.g., "Would the other kid take your toy again?") to minimise the likelihood that the experimenters would suggest to the children that subsequent provocation may occur. Because children could describe numerous different endings (e.g., "We would play together," "We would keep fighting," "I would walk away'), this item reflected a conservative assessment of children's expectations for subsequent problems. Indeed, $41 \%$ of the children's responses did not include provocation by either child (e.g., "We would take turns," "I would keep playing"). Of interest in this study were children's expectations of subsequent provocation by the peer and by themselves; thus, responses to this one item were coded separately for whether children expected the peer to provoke them and for whether they expected to provoke the peer themselves "later that day." An incident was considered provoking if the participant reported that one of the children performed an oppositional act toward the other child without first being provoked. For peer provocation, responses were coded as a 1 if the child reported that the peer would provoke him/her without first being provoked by the participant (e.g., "The other kid stoled the hamster from me," "That kid would erase my thing that I drawed so hard") and as a 0 if the child did not report peer provocation. For expectations of provocation by themselves, children's responses were coded as a 1 if they expected to provoke the peer (e.g., "I would say 'I don't want to play with you'," "I would push that kid down") and as a 0 if they did not expect to provoke the peer. Separate scores reflecting the proportion of times the children expected subsequent provocation by the peers and by themselves were created and used in subsequent analyses. To obtain reliability, a second indepen- dent research assistant also coded expectations of provocation for $33 \%$ of the children's responses ( $\kappa s=.92$ and .74 for provocation by peer and self, respectively).

\section{Results}

In preliminary analyses, the experimenters' verbal portrayal of the conflict vignettes, including whether the conflict role and intensity manipulations were successful and whether the vignettes were verbally portrayed similarly across children and vignettes, was examined. The interrelations among the dependent variables also were examined. The major analyses involved conducting separate 2 (Intensity condition) $\times 2$ (Conflict Role condition) × 2 (Gender) repeated-measures analyses of variance (ANOVAs) for children's expectations of conflict escalation, expectations of mad reactions, expectations of subsequent provocation by the peer, and expectations of subsequent provocation by themselves. ${ }^{1}$ For each ANOVA, conflict role and gender were between-subjects variables and intensity was a within-subjects variable. Means and standard deviations are presented for all the main effects and for the significant two-way interactions between conflict role and intensity in Table 1 and the interrelations among the dependent variables are shown in Table 2.

\section{Portrayal of the conflict vignettes}

To determine whether the intensity levels of the experimenters' verbal presentations of the conflict vignettes varied across the intensity conditions but were similar across the conflict role conditions and for boys and girls, a 2 (Intensity condition) $\times 2$ (Conflict Role condition) × 2 (Gender) repeated-measures analysis of variance (ANOVA) was conducted on the intensity of the experimenters' presentation of the vignettes (as rated by a trained research assistant). There was a significant main effect for the intensity condition, $F(1,92)=1102.84, p<$ .001 . As intended, experimenters' verbal presentations of the vignettes were rated as more intense in the high-intensity condition $(M=4.25, S D=0.58)$ than in the low-intensity condition $(M=1.64, S D=0.54)$. The main effects of gender and conflict role, as well as the two-way interactions between each of the variables, were not significant, indicating that the verbal intensity of the vignettes was similar across the two conflict role conditions and for boys and girls. To determine if the experimenters' verbal intensity was similar for boys and girls across all of the vignettes, a 2 (Gender) $\times 4$ (Vignette; i.e., blocks, rabbit, cleaning up, cash register) repeatedmeasures ANOVA was conducted on the experimenters' verbal intensity (as rated by a trained research assistant). There were no significant main effects or interactions, indicating that the vignettes were verbally presented with similar intensity levels to boys and girls across the four different vignettes.

To determine whether the participants accurately reported who initiated the conflicts in each condition, a 2 (Conflict Role

\footnotetext{
${ }^{1}$ Although a relatively narrow age range (i.e., 4-, 5-, and 6-year-olds) was examined and there were no specific predictions regarding age, age was initially included in analyses. However, there were no significant main effects of age or interactions with age and thus, age was dropped from all analyses.
} 
Table 1

Means and standard deviations for the major variables

\begin{tabular}{|c|c|c|c|c|c|c|c|c|}
\hline \multirow[b]{4}{*}{ Measure } & \multicolumn{4}{|c|}{ Main effects } & \multicolumn{4}{|c|}{ Conflict Role $\times$ Intensity interaction } \\
\hline & \multicolumn{2}{|c|}{ Conflict role } & \multicolumn{2}{|c|}{ Intensity } & \multicolumn{2}{|c|}{ Low-intensity } & \multicolumn{2}{|c|}{ High-intensity } \\
\hline & Initiator & Responder & Low & High & Initiator & Responder & Initiator & Responder \\
\hline & $M(S D)$ & $M(S D)$ & $M(S D)$ & $M(S D)$ & $M(S D)$ & $M(S D)$ & $M(S D)$ & $M(S D)$ \\
\hline \multicolumn{9}{|l|}{ Expectations about the conflict } \\
\hline Conflict escalation ${ }^{\mathrm{a}}$ & $3.00(1.00)$ & $3.28(0.84)$ & $2.94(1.21)$ & $3.31(1.01)$ & $2.65(1.26)$ & $3.21(1.11)$ & $3.25(1.15)$ & $3.36(0.87)$ \\
\hline Mad reactions ${ }^{\mathrm{b}}$ & $1.21(0.96)$ & $1.46(0.98)$ & $1.24(1.05)$ & $1.44(1.10)$ & & & & \\
\hline Perceptions of self as initiator ${ }^{c}$ & $0.42(0.32)$ & $0.12(0.22)$ & $0.23(0.34)$ & $0.31(0.39)$ & & & & \\
\hline \multicolumn{9}{|l|}{$\begin{array}{l}\text { Expectations for subsequent } \\
\text { interactions }\end{array}$} \\
\hline Provocation by peer ${ }^{c}$ & $0.39(0.26)$ & $0.54(0.34)$ & $0.43(0.39)$ & $0.50(0.40)$ & $0.30(0.34)$ & $0.55(0.40)$ & $0.48(0.40)$ & $0.52(0.41)$ \\
\hline Provocation by self ${ }^{\mathfrak{c}}$ & $0.11(0.21)$ & $0.09(0.19)$ & $0.10(0.25)$ & $0.09(0.22)$ & & & & \\
\hline
\end{tabular}

${ }^{\mathrm{a}}$ Possible scores ranged from $1-5$.

${ }^{\mathrm{b}}$ Possible scores ranged from $0-3$.

cProportion score.

Note: Means for the two-way interaction between conflict role and intensity are shown only for variables for which there was a significant interaction.

condition $) \times 2$ (Intensity condition) $\times 2$ (Gender) repeatedmeasures ANOVA was conducted on the proportion of times children reported that they initiated the conflict. There was a significant main effect for the conflict role condition, $F(1,76)$ $=19.73, p<.001$. Children in the "initiator" condition reported that they initiated the conflicts more often than did children in the "recipient" condition (see Table 1).

\section{Children's expectations about the conflict}

To examine the main effects of intensity, conflict role, and gender, as well as the interactive effects of these variables on children's expectations regarding the conflict vignettes, separate 2 (Intensity condition) $\times 2$ (Conflict Role condition) $\times 2$ (Gender) repeated-measures ANOVAs were conducted for expectations of conflict escalation and of mad reactions to conflict. The two-way interactions between intensity and gender and between conflict role and gender, as well as the three-way interaction between intensity, conflict role, and gender, were not significant for either of the analyses on children's expectations about conflict and will not be discussed.

Expectations of conflict escalation. As predicted, children expected conflict to escalate more in the high-intensity condition than in the low-intensity condition, $F(1,90)=$ $9.69, p<.01$. However, consistent with hypotheses, this main effect was qualified by a significant interaction between conflict role and intensity, $F(1,90)=4.10, p<.05$. Follow-up comparisons indicated that, for low-intensity conflicts, responders reported significantly more expectations of conflict escalation than did initiators, $F(1,92)=6.53, p<.02$. In contrast, conflict role did not produce a significant effect for high-intensity conflicts, $F(1,92)=.35$, n.s. Findings also revealed that girls $(M=3.42, S D=0.82)$ expected more escalation than did boys $(M=2.86, S D=0.95), F(1,90)=$ $7.74, p<.01$. Means and standard deviations for main effects and the significant interaction between conflict role and intensity are displayed in Table 1 .

Expectations of mad reactions. Consistent with predictions, children expected to be angrier in the high-intensity condition than in the low-intensity condition (see Table 1 ), $F(1,92)=$ 3.98, $p<.05$. However, contrary to predictions, the main effect of conflict role, as well as the interaction between intensity and conflict role, were not significant, $F_{\mathrm{s}}(1,92)=$ 1.36 and 1.22 , n.s., respectively.

\section{Children's expectations for subsequent interactions}

To examine the main effects of intensity, conflict role, and gender, as well as their interactive effects on children's expectations for subsequent interactions with the peer from the conflict vignettes, separate 2 (Intensity condition) $\times 2$

Table 2

Zero-order correlations between the dependent variables

\begin{tabular}{|c|c|c|c|c|}
\hline Expectations of: & Conflict escalation & Mad reactions & Provocation by peer & Provocation by self \\
\hline 1. Conflict escalation & - & & & \\
\hline 3. Provocation by peer & $.19^{+}$ & $.19^{+}$ & - & \\
\hline 4. Provocation by self & $.19^{+}$ & -.08 & $-.37^{\star \star \star}$ & - \\
\hline
\end{tabular}

${ }^{+} p<.10 ;{ }^{\star \star \star} p<.001$.

Note: $d f=94$ for each test of correlation. 
(Conflict Role condition) $\times 2$ (Gender) repeated-measures ANOVAs were conducted for expectations of subsequent provocation by the peer and by themselves. The two-way interaction between conflict role and gender and the three-way interaction between intensity, conflict role, and gender were not significant for either of the analyses on children's expectations for subsequent interactions and will not be discussed.

Expectations of provocation by peer. Consistent with predictions, children in the "responder" condition expected the peer to provoke them during subsequent interactions more often than did children in the "initiator" condition, $F(1,92)=5.38$, $p<.03$. However, the effect of conflict role was not the same across both levels of intensity as the two-way interaction between conflict role and intensity was significant, $F(1,92)=$ $4.20, p<.05$. Follow-up comparisons indicated that, for lowintensity conflicts, children in the "responder" condition expected the peer to provoke them more often than did children in the "initiator" condition, $F(1,94)=11.16, p=$ .001 . In contrast, children expected the peer to provoke them relatively often during interactions following high-intensity conflicts regardless of their conflict role, $F(1,94)=0.25$, n.s. Means and standard deviations for main effects and the significant interaction between conflict role and intensity are presented in Table 1.

The two-way interaction between intensity and gender also was significant, $F(1,92)=5.17, p<.03$. Specifically, followup comparisons revealed that, for low-intensity conflicts, girls $(M=0.51, S D=0.39)$ expected the peer to provoke them more often than did boys $(M=0.34, S D=0.37), F(1,94)=$ 4.53, $p<.04$. In contrast, gender did not have an effect on expectations of peer provocation for high-intensity conflicts $(M \mathrm{~s}=0.47$ and $0.53, S D \mathrm{~s}=0.41$ and 0.41 , for girls and boys, respectively), $F(1,94)=.57$, n.s.

Expectations of provocation by self. The main effects of conflict role, intensity, and gender, as well as their interactions, were not significant. As can be seen in Table 1, children were unlikely to expect that they would provoke the peer during a subsequent interaction, regardless of condition.

\section{Discussion}

Although children typically blame others for starting their conflicts (McGuire et al., 2000; Shantz, 1993), the present findings indicate that they distinguish between conflicts that they initiate and those that are initiated by other children. More importantly, findings also show that young children's expectations of peer conflict vary in meaningful ways in these different situations. Specifically, responders tended to expect conflict to escalate more than did initiators and expected the same peer from the conflict to provoke them later more often than did initiators, particularly following low-intensity conflicts.

The present findings largely supported hypotheses regarding children's conflict role and are consistent with previous work suggesting that young children perceive conflicts that they initiate in a relatively positive manner (Arsenio et al., 2000; A.L. Miller \& Olson, 2000). Ross et al. (1999) pointed out that the processes underlying children's positive self-views in the context of conflict remain unclear as they could reflect biased interpretations of the events or deliberate attempts by the children to portray themselves as less blameworthy and more innocent than the other children in the conflicts. Although more recent work suggests children's self-serving biases reflect their desire to present themselves in a relatively positive manner (Ross et al., 2004), additional research is needed to further explore the unique and joint contributions of memory processes, interpretation biases, and self-presentational concerns to children's biased reports of conflict. In the present study, it is important to note that children reported that they initiated conflict more often when they did actually initiate than when a peer initiated conflict. Thus, children's positive expectations regarding conflict do not seem to be based on biased perceptions of who started the conflict, and our findings are consistent with Ross et al.'s (2004) work suggesting children's desire to present themselves in a positive light.

As predicted, children reported more expectations of conflict escalation and expected to be angrier for high-intensity conflicts than for low-intensity conflicts. Preschoolers' expectations are consistent with previous work demonstrating that young children's actual strategies during peer conflict are based on previous strategies employed during the conflict such that conflicts that involve strong insistence tend to escalate and elicit further opposition, whereas conflicts involving justifications for behaviour and compromise tend to de-escalate or remain relatively mild (Eisenberg \& Garvey, 1981). Thus, children in the present study seemed to recognise the dyadic nature of the conflicts such that their expectations were consistent with the behavioural flow and emotional climate of the vignettes.

Consistent with hypotheses, the main effects of conflict role and intensity were qualified by significant interactions between conflict role and intensity on children's expectations of conflict escalation and of subsequent provocation by the peer. Specifically, for low-intensity but not high-intensity conflict, responders expected conflict to escalate more and expected the peer to provoke them during a subsequent interaction more often than did initiators. The oppositional nature of lowintensity conflicts may be salient to preschoolers who are responders during conflict rather than initiators because they tend to focus on their own gains or losses following disputes (Arsenio \& Lover, 1995) and to perceive others' transgressions towards them as being particularly malicious (Ross et al., 1999, 2004). Furthermore, young children's tendencies to focus on their own outcomes may lead them to expect low-intensity conflicts that they initiate to have relatively constructive resolutions and outcomes. In contrast, once conflict escalates, it may be particularly difficult for children to expect constructive conflict resolution, even if they initiated it. Moreover, who initially started the opposition may not matter in high-intensity conflicts because the use of nonconstructive strategies (e.g., strong insistence) by either child is likely to elicit subsequent nonconstructive reactions and prolong problematic interactions (Eisenberg \& Garvey, 1981). Indeed, children expected subsequent provocation from the peer to occur often following high-intensity conflict regardless of their role in the conflict.

The present findings have implications for children's peer relationships. Laursen, Hartup, and Koplas (1996) hypothesised that how children handle their conflicts can play a large role in determining whether oppositional interactions facilitate or hinder interdependent relationships such as friendships. 
Understanding the short-term effects of interpersonal conflict on young children's peer interactions can provide insight into how these broad developmental effects on peer relations may occur. Findings from the present study indicate that conflict can have short-term harmful effects on peer interactions, as children in general expected conflict to escalate when a peer initiated opposition and subsequent problems with a peer who initiated conflict, which may lead them to avoid that peer in the future. Indeed, preschoolers prefer to play with responders to initial opposition in conflict than initiators (Hay et al., 1992) and children who initiate conflict often or who typically react in a nonconstructive manner to peer opposition tend to be disliked by their peers (Bryant, 1992; Dodge, Coie, Pettit, \& Price, 1990; Murphy \& Eisenberg, 1997; Olson, 1992; Shantz, 1987; Shantz \& Shantz, 1985). Further, kindergartners who judge a peer negatively expect some stability in the peer's behaviour, suggesting that children who get off to a bad start in early childhood could be judged negatively by peers and may have difficulty gaining their approval and friendship (Stipek \& Daniels, 1990). Given the potential harm that conflict can have on the development of peer relations, it is important for children to develop the emotional and behavioural skills needed to deal constructively with a variety of peer conflict situations.

It is important to note that children expected the peer to provoke them again when the peer initiated conflict, but they did not reportedly expect themselves to provoke the peer again when they initiated conflict. Thus, although young children are able to recognise consistency in their own behaviour (Eder, 1989), their reported expectations reflect a self-serving bias when they initiate conflict. However, it is unclear why children tended to report that they would not provoke the peer "later that day," as this could reflect a bias in children's thinking about conflict or a self-presentational bias in their reporting.

Although the interactive effects of conflict role and intensity were of primary interest in the present study, the role of gender was also examined. Results indicated that girls expected conflict to escalate more than did boys. Although young girls in general are better at avoiding peer conflict (P.M. Miller et al., 1986) and exhibit more prosocial and constructive behaviour during conflict (Chung \& Asher, 1996; Dunn \& Herrera, 1997; Eisenberg et al., 1994; Hay et al., 1992; P.M. Miller et al., 1986; Murphy \& Eisenberg, 2002; Rose \& Asher, 1999) than boys, the present findings suggest that girls' expectations and perceptions of conflict may be more sensitive to negative cues once conflict occurs than are boys'. This greater sensitivity to conflict negativity may motivate girls to engage in behaviours that are likely to de-escalate conflict.

Findings also revealed a significant interaction between gender and intensity for expectations of subsequent provocation by the peer. Specifically, following low-intensity conflicts, girls expected the peer to provoke them during a subsequent interaction more often than did boys. Because girls tend to be more socially oriented and sensitive to emotional cues than are boys (see Ruble \& Martin, 1998, for a review), young girls may be particularly sensitive to even mild conflicts with their peers. Consequently, young girls may be particularly likely to focus on the implications of all disputes, including lowintensity conflicts, for subsequent interactions with the same peer. Young boys, on the other hand, engage in more roughand-tumble, physical play than do girls (Humphreys \& Smith, 1984) and thus, they may not perceive low-intensity conflict as oppositional and negative. In contrast, girls and boys did not differ in their expectations of subsequent provocation by the peer following high-intensity conflict. The oppositional nature of the high-intensity conflict seemed to be clear and salient to all children as both boys and girls tended to expect subsequent provocation by the peer following high-intensity conflict.

Although conflict role and intensity have been shown to affect children's behavioural and emotional reactions during and following peer conflict (e.g., Arsenio \& Killen, 1996; Laursen \& Hartup, 1989), the present findings are unique in that they demonstrate that preschoolers think about conflict differently, depending on their role in conflict and the intensity of conflict. Researchers increasingly have recognised the importance of assessing children's representations and understanding of conflict (Hay et al., 1992; Iskandar, Laursen, Finkelstein, \& Fredrickson, 1995; McGuire et al., 2000; Murphy \& Eisenberg, 2002; Ross et al., 1999, 2004; Shantz, 1993; Wilson et al., 2004). Although observations of children's conflict-related reactions (Arsenio \& Killen, 1996; Laursen \& Hartup, 1989; O’Brien et al., 1999) provide important information regarding what happens during these events, questioning them about conflict provides researchers with insiders' views of peer conflict and information regarding the meaning children give to these events (Shantz, 1993). Moreover, children's expectations of conflict are likely to influence their reactions to actual conflict as children's representations of situations guide their interpretations of and behaviours in subsequent interactions (Crick \& Dodge, 1994). Thus, the present findings provide further support for studying young children's representations and understanding of conflict, although further research is needed to more fully understand how children's expectations are related to their actual behaviour with peers. For example, Arsenio and colleagues (Arsenio \& Cooperman, 1996; Arsenio \& Kramer, 1992) suggest that children's tendency to expect victimisation of others to produce positive emotions and material gains may undermine their efforts to resolve conflicts constructively and lead to a pattern of victimisation of others, yet few children actually engage in chronic victimisation (see Olweus, 1993).

Further, although children's enacted responses to hypothetical vignettes have been shown to be predictive of their actual behaviour in naturalistic settings (e.g., Eisenberg et al., 1994; Mize \& Ladd, 1988), there also are some important differences between children's reactions to hypothetical versus actual conflict situations. Specifically, children may become more emotionally aroused when they are victimised or provoked in real-life than in hypothetical vignettes because their own wellbeing or material possessions may be threatened, but they may not feel particularly threatened or angry when responding to hypothetical opposition. Additionally, the puppet procedure used in the present study did not include facial expressions, which are likely to be evident during naturally-occurring peer conflict. These departures from actual conflict may explain why initiators and responders did not differ in their expectations of mad reactions during conflict. Furthermore, previous research indicates that children's strategies for resolving conflicts with peers vary across hypothetical and actual conflicts such that children favour the use of negotiation (e.g., sharing, talking things out) over coercion (e.g., commands, aggression) or disengagement (e.g., changing topic, withdrawing from interaction) in hypothetical conflicts but resolve actual conflicts with coercion more often than with negotiation or disengagement (Iskandar et al., 1995; see 
Laursen, Finkelstein, \& Betts, 2001). Thus, the self-serving biases evident in the present findings may, in part, be an artifact of the hypothetical conflicts depicted in the puppet procedure. Yet, although young children in general tend to perceive hypothetical transgressions as more serious and wrong than actual transgressions enacted by a peer (Smetana, Schlagman, \& Adams, 1993), our findings show that they also view hypothetical conflicts that they initiate as less negative than those that are started by a peer. Moreover, when considered in conjunction with previous work demonstrating children's positive view of themselves in their reports of sibling conflict (Ross et al., 1999, 2004; Wilson et al., 2004), and initiators' observed emotions and behaviours during naturallyoccurring peer conflict (Arsenio et al., 2000; Arsenio \& Killen, 1996), the present findings provide further support for a selfserving bias in children's perceptions and expectations of peer conflict.

Caution is warranted when generalising the present findings to children's expectations about conflicts and interactions with specific peers because the vignettes in the present study involved "another kid" rather than someone in particular, such as a friend. Indeed, children's conflicts with friends are less intense, more often resolved with disengagement and less often with insistence, and result in more post-conflict interaction than their conflicts with neutral peers (Hartup, Laursen, Stewart, \& Eastenson, 1988). Children also interpret the behaviour of liked peers less negatively than similar behaviour of disliked peers (Hymel, 1986). Thus, the effects of conflict role and intensity on children's expectations about conflict and about subsequent interactions might depend on the relationship with the peer.

It also should be noted that these findings may be specific to preschool children. The expectation of the happy victimiser decreases with age, partly because older children have a better understanding of the harm produced by victimisation, although most school-aged children still expect victimisers to feel some positive emotions (Arsenio \& Kramer, 1992). Moreover, with age children have more realistic and less overly positive perceptions of themselves (see Harter, 1998) and they have better perspective-taking abilities as well as a more complex understanding of interpersonal conflict (Selman, 1980). Thus, the effects of conflict role and intensity on expectations of conflict might vary for children of different ages.

In conclusion, the present study extends previous work by showing that young children's expectations about peer conflict vary as a function of their role in the conflict and the overall intensity of the conflict, providing further support for the importance of asking children about their perceptions and representations of conflict. Results also provide support for a self-serving bias in preschoolers' reports of their interactions and relationships with other children (Ross et al., 1999, 2004; Ross, Woody, Smith, \& Lollis, 2000; Wilson et al., 2004). Although young children tend to perceive conflicts they initiate as relatively undisruptive, other children are likely to perceive such events as particularly troublesome and upsetting, suggesting that initiating conflict can have damaging effects on their abilities to make friends and engage in pleasant peer interactions. However, conflict also has the potential to have beneficial effects on the development of perspective-taking and negotiation skills (Piaget, 1932; Shantz \& Hobart, 1989). The present findings further demonstrate the importance of identifying aspects of conflict that increase the likelihood of destructive effects on children's peer relations so that children can be taught strategies for dealing with conflict in a manner that will result in constructive endings and outcomes.

Manuscript received November 2003 Revised manuscript received May 2004 PrEview publication September 2004

\section{References}

Arsenio, W.F., \& Cooperman, S. (1996). Children's conflict-related emotions Implications for morality and autonomy. In M. Killen (Ed.), Children's autonomy, social competence, and interactions with adults and other children: Exploring connections and consequences. New Directions for Child Development, No. 73 (pp. 25-39). San Francisco: Jossey-Bass.

Arsenio, W.F., Cooperman, S., \& Lover, A. (2000). Affective predictors of preschoolers' aggression and peer acceptance: Direct and indirect effects. Developmental Psychology, 36, 438-448.

Arsenio, W.F., \& Killen, M. (1996). Conflict-related emotions during peer disputes. Early Education and Development, 7, 43-57.

Arsenio, W.F., \& Kramer, R. (1992). Victimizers and their victims: Children's conceptions of the mixed emotional consequences of moral transgressions. Child Development, 63, 915-927.

Arsenio, W.F., \& Lover, A. (1995). Children's conceptions of sociomoral affect: Happy victimizers, mixed emotions, and other expectancies. In M. Killen \& D. Hart (Eds.), Morality in everyday life: Developmental perspectives (pp. 87 128). New York: Cambridge University Press.

Astor, R.A. (1994). Children's moral reasoning about family and peer violence: The role of provocation and retribution. Child Development, 65, 1054-1067.

Berndt, T.J., \& Heller, K.A. (1985). Measuring children's personality attributions: Responses to open-ended questions versus trait ratings and predictions of future behavior. In S.R. Yussen (Ed.), The growth of reflection in children (pp. 37-60). Orlando, FL: Academic Press.

Bryant, B.K. (1992). Conflict resolution strategies in relation to children's peer relations. Fournal of Applied Developmental Psychology, 13, 35-50.

Chung, T., \& Asher, S.R. (1996). Children's goals and strategies in peer conflict situations. Merrill-Palmer Quarterly, 42, 125-147.

Crick, N.R., \& Dodge, K.A. (1994). A review and reformulation of social information-processing mechanisms in children's social adjustment. Psychological Bulletin, 115, 74-101.

Dodge, K.A., Coie, J.D., Pettit, G.S., \& Price, J.M. (1990). Peer status and aggression in boys' groups: Developmental and contextual analyses. Child Development, 61, 1289-1309.

Dozier, M. (1991). Functional measurement assessment of young children's ability to predict future behaviour. Child Development, 62, 1091-1099.

Dunn, J., \& Herrera, C. (1997). Conflict resolution with friends, siblings, and mothers: A developmental perspective. Aggressive Behavior, 23, 343-357.

Eder, R.A. (1989). The emergent personologist: The structure and content of

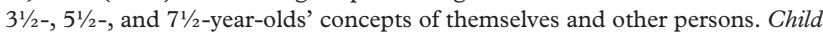
Development, 60, 1218-1228.

Eisenberg, N., Fabes, R.A., Minore, D., Mathy, R., Hanish, L., \& Brown, T. (1994). Children's enacted interpersonal strategies: Their relations to social behavior and negative emotionality. Merrill-Palmer Quarterly, 40, 212-232.

Eisenberg, A.R., \& Garvey, C. (1981). Children's use of verbal strategies in resolving conflicts. Discourse Processes, 4, 149-170.

Harter, S. (1998). The development of self-representations. In W. Damon (Series Ed.) \& N. Eisenberg (Vol. Ed.), Social, emotional, and personality development: Vol. 3. Handbook of child psychology (pp. 553-617). New York: Wiley.

Hartup, W.W., Laursen, B., Stewart, M.I., \& Eastenson, A. (1988). Conflict and the friendship relations of young children. Child Development, 59, 1590-1600.

Hay, D.F., Zahn-Waxler, C., Cummings, E.M., \& Iannotti, R.J. (1992). Young children's views about conflict with peers: A comparison of the daughters and sons of depressed and well women. Fournal of Child Psychology and Psychiatry, 33, 669-683.

Humphreys, A.P., \& Smith, P.K. (1984). Rough-and-tumble in preschool and playground. In P.K. Smith (Ed.), Play in animals and humans (pp. 241-266). Oxford: Basil Blackwell.

Hymel, S. (1986). Interpretations of peer behavior: Affective bias in childhood and adolescence. Child Development, 57, 431-445.

Iskandar, N., Laursen, B., Finkelstein, B., \& Fredrickson, L. (1995). Conflict resolution among preschool children: The appeal of negotiation in hypothetical disputes. Early Education and Development, 6, 359-376.

Laursen, B. (1993). The perceived impact of conflict on adolescent relationships. Merrill-Palmer Quarterly, 39, 535-550.

Laursen, B., Finkelstein, B.D., \& Betts, N.T. (2001). A developmental metaanalysis of peer conflict resolution. Developmental Review, 21, 423-449. 
Laursen, B., \& Hartup, W.W. (1989). The dynamics of preschool children's conflicts. Merrill-Palmer Quarterly, 35, 281-297.

Laursen, B., Hartup, W.W., \& Koplas, A.L. (1996). Towards understanding peer conflict. Merrill-Palmer Quarterly, 42, 76-102.

McGuire, S., Manke, B., Eftekhari, A., \& Dunn, J. (2000). Children's perceptions of sibling conflict during middle childhood: Issues and sibling (dis)similarity. Social Development, 9, 173-190.

Miller, A.L., \& Olson, S.L. (2000). Emotional expressiveness during peer conflicts: A predictor of social maladjustment among high-risk preschoolers. fournal of Abnormal Child Psychology, 28, 339-352.

Miller, P.M., Danaher, D.L., \& Forbes, D. (1986). Sex-related strategies for coping with interpersonal conflict in children aged five and seven. Developmental Psychology, 22, 543-548.

Mize, J., \& Ladd, G.W. (1988). Predicting preschoolers' peer behavior and status from their interpersonal strategies: A comparison of verbal and enactive responses to hypothetical social dilemmas. Developmental Psychology, 24, 782788 .

Murphy, B.C., \& Eisenberg, N. (1997). Young children's emotionality, regulation and social functioning and their responses when they are targets of a peer's anger. Social Development, 6, 18-36.

Murphy, B.C., \& Eisenberg, N. (2002). An integrative examination of peer conflict: Children's reported goals, emotions, and behaviors. Social Development, 11, 534-557.

O'Brien, M., Roy, C., Jacobs, A., Macaluso, M., \& Peyton, V. (1999). Conflict in the dyadic play of 3-year-old children. Early Education and Development, 10, $289-313$

Olson, S.L. (1992). Development of conduct problems and peer rejection in preschool children: A social systems analysis. Fournal of Abnormal Child Psychology, 20, 327-350.

Olweus, D. (1993). Bullies on the playground: The role of victimization. In C.H. Hart (Ed.), Children on playgrounds: Research perspectives and applications (pp. 85-128). Albany, NY: State University of New York Press.

Piaget, J. (1932). The moral judgment of the child. London: Routledge \& Kegan Paul.

Rose, A.J., \& Asher, S.R. (1999). Children's goals and strategies in response to conflicts within a friendship. Developmental Psychology, 35, 69-79.

Ross, H., Ross, M., Wilson, A., \& Smith, M. (1999). The dandelion war. In S.R. Goldman, A.C. Graesser \& P. van den Broek (Eds.), Narrative comprehension, causality, and coherence (pp. 253-277). Mahwah, NJ: Lawrence Erlbaum Associates Inc.

Ross, H., Smith, J., Spielmacher, C., \& Recchia, H. (2004). Shading the truth: Self-serving biases in children's reports of sibling conflicts. Merrill-Palmer Quarterly, 50, 61-85.
Ross, H., Woody, E., Smith, M., \& Lollis, S. (2000). Young children's appraisals of their sibling relationships. Merrill-Palmer Quarterly, 46, 441-464.

Ruble, D.N., \& Martin, C.L. (1998). Gender development. In W. Damon (Series Ed.) \& N. Eisenberg (Vol. Ed.), Social, emotional, and personality development: Vol. 3. Handbook of child psychology (pp. 933-1016). New York: Wiley.

Selman, R.L. (1980). The growth of interpersonal understanding: Developmental and clinical analyses. New York: Academic Press.

Shantz, C.U. (1987). Conflicts between children. Child Development, 58, 283 305.

Shantz, C.U. (1993). Children's conflicts: Representations and lessons learned In R.R. Cocking \& K.A. Renninger (Eds.), The development and meaning of psychological distance (pp. 185-202). Hillsdale, NJ: Lawrence Erlbaum Associates Inc.

Shantz, C.U., \& Hobart, C.J. (1989). Social conflict and development: Peers and siblings. In T.J. Berndt \& G.W. Ladd (Eds.), Peer relationships in child development (pp. 71-94). New York: Wiley.

Shantz, C.U., \& Shantz, D.W. (1985). Conflict between children: Socialcognitive and sociometric correlates. In M.W. Berkowitz (Ed.), Peer conflict and psychological growth. New Directions for Child Development, No. 29 (pp. 3 21). San Francisco: Jossey-Bass.

Shantz, D.W. (1986). Conflict, aggression, and peer status: An observational study. Child Development, 57, 1322-1332.

Smetana, J.G., Campione-Barr, N., \& Yell, N. (2003). Children's moral and affective judgments regarding provocation and retaliation. Merrill-Palmer Quarterly, 49, 209-236.

Smetana, J.G., Daddis, C., Toth, S.L., Cicchetti, D., Bruce, J., \& Kane, P. (1999). Effects of provocation on maltreated and nonmaltreated preschoolers' understanding of moral transgressions. Social Development, 8, 335-348.

Smetana, J.G., Schlagman, N., \& Adams, P.W. (1993). Preschool children's judgments about hypothetical and actual transgressions. Child Development, 64, 202-214.

Stipek, D.J., \& Daniels, D.H. (1990). Children's use of dispositional attributions in predicting the performances and behavior of classmates. Fournal of Applied Developmental Psychology, 11, 13-28.

Wilson, A.E., Smith, M.D., Ross, H.S., \& Ross, M. (2004). Young children's personal accounts of their sibling disputes. Merrill-Palmer Quarterly, 50, 3960.

Yuill, N., \& Pearson, A. (1998). The development of bases for trait attribution: Children's understanding of traits as causal mechanisms based on desire. Developmental Psychology, 34, 574-586. 